\title{
Investigation of mechanical properties of mortars with carbon fiber using multi slice computed tomography
}

\author{
Investigación de propiedades mecánicas de morteros con fibra de carbono, usando tomografía \\ computarizada de torsión múltiple
}

Ozlem Celik Sola (Main Author) (Corresponding author)

Department of Civil Engineering, Engineering Faculty, Istanbul University

Turkey

celik@istanbul.edu.tr

\section{Savaş Erdem}

Department of Civil Engineering, Engineering Faculty, Istanbul University

Turkey

savas.erdem@istanbul.edu.tr

\section{Levent Bostancı}

School of Advanced Vocational Studies, Beykent University

Turkey

leventbostanci@beykent.edu.tr

\section{Cengiz Duran Atis}

Department of Civil Engineering, Engineering Faculty, Erciyes University

Turkey

cdatis@erciyes.edu.tr

\section{Baris Sayin}

Department of Civil Engineering, Engineering Faculty, Istanbul University

Turkey

barsayin@istanbul.edu.tr

Manuscript Code: 887

Date of Acceptance/Reception: 03.04.17/13.02.2017

DOI: 10.7764/RDLC.16.1.167

\begin{abstract}
Carbon fibers (CFs) in the cement mortars are used in order to improve characteristics properties of the composite materials such as mechanical properties. Moreover, the uniformity of fiber dispersion is significant aspect for improvement of the composites. Computed Tomography (CT) imaging is a fully nondestructive technique to view features in the interior of opaque solid objects to obtain digital information on their properties. In this study, firstly, flexural test was conducted were investigated for $4 \times 4 \times 16 \mathrm{~cm}$ samples incorporated with carbon fiber at 2- and 7-days curing. Secondly, the images that were obtained by using multi-slice CT technique. Finally, the compressive strength properties of the mortars mixed with carbon fiber were discussed. According to the test results, the dispersion and orientation of CFs in the samples have a remarkable impact on mechanical properties of the composites.
\end{abstract}

Key words: Carbon fiber, computed tomography (CT), compressive strength, flexural strength.

\section{Resumen}

En morteros de cemento se utilizan fibras de carbono (FC), para mejorar las propiedades características de los materiales compuestos, tales como propiedades mecánicas. Además, la uniformidad de la dispersión de fibras es un aspecto significativo para la mejora de los compuestos. La tomografía computarizada (CT) es una técnica completamente no destructiva, para observar características en el interior de objetos sólidos opacos para obtener información digital sobre sus propiedades. En este estudio, en primer lugar, se llevó a cabo la prueba de flexión, utilizando $4 \times 4 \times 16$ $\mathrm{cm}$ de muestras incorporadas con fibra de carbono en 2 y 7 días de curado. En segundo lugar, se obtuvieron imágenes mediante la técnica de torsión múltiple. Finalmente, se discutieron las propiedades de resistencia a la compresión de los morteros mezclados con fibra de carbono. De acuerdo con los resultados de la prueba, la dispersión y orientación de CFs en las muestras tienen un impacto notable en las propiedades mecánicas de los compuestos. 
The utilization of carbon fibers (CF) in the cement matrix started in the early 1990s. Carbon fiber reinforced cementbased composites have important features compared with ordinary cement materials such as light weight, high durability and excellent mechanical properties (Baeza et al., 2013; Graham et al., 2013). An increase of $85 \%$ in flexural strength, $205 \%$ in flexural toughness and $22 \%$ in compressive strength were obtained. Moreover, carbon fibers (CF) are added to cement based mixtures in order to make better both crack resistance and thermal property (Grace and Singh, 2005; Eva et al., 2005). In addition, CFs have more advantages due to increasing the conductivity and improving the electromagnetic behavior of cement. Thus, the composite materials obtained by adding CF can also be used as smart structural materials in structural engineering applications (Kezhi et al., 2008; Mary et al., 2007). However, the rheological and mechanical properties of the composites are affected by dispersion of CFs (Ozyurt et al., 2007). Besides, the increasing CF content reduces the workability of the mixture during the preparation. Therefore, effective usage of CFs in cement-based mixed is required in order to obtain uniform dispersion of CF in the mixture (Wang et al., 2008). The air void content is also affected by CF dispersion in cement. As it is known that the compressive strength of the composites is generally affected negatively because of the high air void content (Zhandarov and Mader, 2005). The effect of carbon fiber dispersion on the mechanical properties of the composites was studied by Wang et al., 2008. According to their study the reinforcement capacity of carbon fibers is deal with the dispersion of the fibers in the mixtures. Thereby, the uniformity for the dispersion of the carbon fibers in the mixtures is seen as a significant parameter for improvement of the composite's properties. Additionally, Cao and Chung (2001) used short carbon fibers in order to reinforce mortar mixtures and they observed an improvement for these mortar mixtures with respect to usage of acrylic dispersion intended to mortars by the mass of $15 \%$.

As the uniformity of fiber dispersion is considerable aspect for improvement of the composites, investigation of the fiber dispersion has started to be challenging subject. In order to observe CFs dispersion uniformity in the mixtures, Shui and Stroeven (1999) used impedance estimations. In another study, the ability of AC-impedance spectroscopy was evaluated in order to show the dispersion of the carbon fibers in the cement base mortars (Ozyurt et al., 2006; Woo et al., 2005). Furthermore, X-ray CT can be used a fully nondestructive method for investigating features in the inner part of the opaque particles to detect digital data in their features. Void-ratio, -area, and -size of the air in cement asphalt emulsion composites were measured with using X-ray CT (Wang and Xiao, 2012). On the other hand, Cosmi and Bernasconi (2013) utilized micro-CT method to investigate the fatigue results for the polymers that were reinforced by short fiber. The description technique of fiber dispersion in 3D space by micro-CT imaging was observed Liu et al. (2013), and they showed the influence of aggregate on fiber dispersion and spacing between fibers. A watershed segmentation algorithm was developed by Lee et al. (2009) in order to investigate a sole fiber view obtained by the archetype thresholding algorithm. A fluorescence technique for specifying the fluorescence view by using a microscope on the mixtures was developed by Torigoe et al. (2003), they presented not only the degree of distribution, but also the ultimate tensile strain of the mixtures.

The paper presents a beneficial technique for the observation of the distribution of carbon fibers in the mixtures after the flexural strength test was conducted for 2- and 7-days curing samples. Also, the compressive strength properties of the mortars mixed with carbon fiber were obtained. In a limited number of studies up to now, CT images have been used to determine homogeneity distributions prior to the mechanical strength of the specimens. Prior to the determination of the mechanical properties of the materials in previous studies, the locations of the materials in the matrix were examined by CT technique. But however, this study will be able to determine the effects on mechanical properties when the materials change their positions in the matrix. In addition, the differences in the dimensional changes of the materials and their effects on the mechanical properties reveal the novelty and originality of the study. Therefore, uniform dispersion of the carbon fibers in the mixtures has a key role on mechanical and durability properties of the composites.

Materials and methods

CEM I-42.5R (Portland cement) conforming to ASTM C150/C150M (2015) was used in the lab test. Table 1 presents the physical- and chemical-properties of the used cement. The carbon fiber was obtained by Arkem Kimya Company from Turkey and the type of this fiber is Kuralon Recs $15 \times 8 \mathrm{~mm}$. The some physical and mechanical properties of the carbon fiber (CF) are given in Table 2. The standard Rilem sand, which has unit weight of $1.352 \mathrm{~kg} / \mathrm{m} 3$ and specific gravity of $2.563 \mathrm{~kg} / \mathrm{m3}$, was used for preparing the cement mortars.

For producing all cement mortar mixtures, sand/cement/water ratio was taken as 3/1/0.5, respectively. According to this ratio, $1350 \mathrm{~g}$ standard Rilem sand, $225 \mathrm{~g}$ water and $450 \mathrm{~g}$ cement were mixed to obtain all cement mortar 
mixtures by weight. As it is clearly seen from mixing program that carbon fibers were mixed with cement mortar by weights of $2,4,6,8$ and $10 \mathrm{~g}$ to produce samples with dimensions of $4 \times 4 \times 16 \mathrm{~cm}$. Table 3 shows the mix design of the cement mortar mixtures with CF.

\begin{tabular}{llc} 
& \multicolumn{2}{c}{ Table 1. Properties of Portland cement used in the tests. } \\
\hline & & Portland cement (PC) \\
\hline Chemical & $\mathrm{CaO}$ & 64.34 \\
analysis & $\mathrm{SiO}_{2}$ & 20.24 \\
& $\mathrm{Al}_{2} \mathrm{O}_{3}$ & 4.57 \\
& $\mathrm{Fe}_{2} \mathrm{O}_{3}$ & 4.00 \\
& $\mathrm{MgO}$ & 1.13 \\
& $\mathrm{SO}_{3}$ & 3.30 \\
& $\mathrm{~K}_{2} \mathrm{O}$ & 0.52 \\
& $\mathrm{Na}_{2} \mathrm{O}$ & 0.20 \\
& $\mathrm{Cl}^{-}$ & 0.017 \\
& Loss on ignition & 1.36 \\
& Dissolved ruins & 0.18 \\
Physical & Specific gravity (g/c) & 3.16 \\
& Fineness $(45 \mu)$ & 2.30 \\
& Blaine $\left(\mathrm{cm}^{2} / \mathrm{g}\right)$ & 4182 \\
\hline
\end{tabular}

After completing the compressive strength and flexural tensile strength tests of the samples for 2- and 7-days curing, the internal structure of each test specimen was imaged using the multi-slice computed tomography CT System (Ge Brivo 325 CT). The thicker sections obtained from the imaged samples that is observed at less time compared with conventional CT results could be provided with multi-slice technique. By the using of these sections with reconstruction method, 3D images could be obtained.

Compressive strength tests for all mortar mixtures incorporated with CFs were conducted with respect to curing of 2and 7-days curing by using $4 \times 4 \times 16 \mathrm{~cm}$ specimens. In order to estimate the compressive strength tests results, the loading rate was selected $5 \mathrm{~kg} \cdot \mathrm{f} \cdot \mathrm{s}^{-1}$ as constant in all tests. The ASTM C348 test procedure was used to evaluate the flexural strength of the mortar using a sample size of $4 \times 4 \times 16 \mathrm{~cm}$ (ASTM 2011a). A three-point loading set up was used with a loading rate of $2640 \pm 110 \mathrm{~N}$.

\begin{tabular}{ccccc}
\hline & Table 2. Physical and mechanical properties of the carbon fiber (CF). \\
\hline & $\begin{array}{c}\text { Diameter } \\
(\mathrm{mm})\end{array}$ & $\begin{array}{c}\text { Length } \\
(\mathrm{mm})\end{array}$ & $\begin{array}{c}\text { Tensile strength } \\
(\mathrm{GPa})\end{array}$ & $\begin{array}{c}\text { Modulus of elasticity } \\
(\mathrm{GPa})\end{array}$ \\
\hline $\operatorname{Rec} 15 \times 8 \mathrm{~mm}(\mathrm{CF})$ & 40 & 8 & 1.6 & 42 \\
\hline
\end{tabular}

\begin{tabular}{|c|c|c|c|c|c|}
\hline Sample & $w / c$ & $\mathrm{PC}(\mathrm{g})$ & $C F(g)$ & w (g) & Rilem sand (g) \\
\hline $\mathrm{M}_{1}$ & \multirow{6}{*}{0.5} & \multirow{6}{*}{450} & 0 & \multirow{6}{*}{225} & \multirow{6}{*}{1350} \\
\hline $\mathrm{M}_{2}$ & & & 2 & & \\
\hline$M_{3}$ & & & 4 & & \\
\hline $\mathrm{M}_{4}$ & & & 6 & & \\
\hline $\mathrm{M}_{5}$ & & & 8 & & \\
\hline$M_{6}$ & & & 10 & & \\
\hline
\end{tabular}

\section{Compressive- and flexural-strength of the samples}


The compressive strength of cement mortars incorporated with different dosages of CFs at 2 curing ages (2- and 7days curing) are given in Table 4. It can be clearly seen from the table that only M2 mix at 2- and 7-days curing increased the compressive strength slightly. However, the compressive strength of the other samples decreased with an increase in the amount of CFs. It seems that an increase amount of CF decreases the compressive strength of the samples. Strength enhancement of CFs can be attributed to reduction in the content of $\mathrm{Ca}(\mathrm{OH})_{2}$ which does not have any cementing property and production of hydrated calcium silicate (CSH) that plays a vital role in mechanical characteristics of cement paste (Gao et al., 2002; Rao, 2003). A possible reason for this reduction may be that carbon fibers act as crack arresters. It is obvious that increase in CF dosage decreases the compressive strength of the mortars. This is understandable because large contents of carbon fibers are more difficult to disperse uniformly. Therefore, fibers form clusters and create more micro-defects in cement matrix which inevitably reduces the compressive strength of mortar (Sadrmomtazi et al., 2009).

\begin{tabular}{lccccc} 
& \multicolumn{2}{c}{ Table 4. Compressive- and flexural-strength of the samples for 2-and 7-days curing. } \\
\cline { 2 - 3 } Sample & \multicolumn{2}{c}{ Compressive strength (MPa) } & & \multicolumn{2}{c}{ Flexural strength (MPa) } \\
\cline { 2 - 3 } \cline { 5 - 6 }$M_{1}$ & 2 days curing & 7 days curing & & 2 days curing & 7 days curing \\
$M_{2}$ & 28.5 & 42.8 & & 4.8 & 7.0 \\
$M_{3}$ & 29.5 & 44.7 & & 5.0 & 7.2 \\
$M_{4}$ & 26.1 & 38.9 & & 4.5 & 6.4 \\
$M_{5}$ & 24.8 & 38.1 & & 4.4 & 5.7 \\
$M_{6}$ & 23.4 & 35.0 & & 3.6 & 5.2 \\
\hline
\end{tabular}

The flexural strength of mortar specimens is also presented in Table 4. Results of carbon fiber reinforced specimens showed that the flexural strength in carbon fiber reinforced mortars were lower than that of mortars without carbon fibers. The values of flexural strength of cement composites decreased with increasing of carbon fiber amount at all curing days. However, only $\mathrm{M}_{2}$ mix at 2- and 7-days curing increased the flexural strength slightly just as compressive strength results of the samples. The microstructure of cement mortar at the interfacial between carbon fiber and matrix is the most important region influences of the fibers effectiveness. The addition of CFs does not strengthen this weak region through reduction of the internal porosity especially in the transition layer by consumption of porous portlandite crystals which array in the interfacial between fiber and matrix. The main reason of this reduction may be explained as non-uniform dispersion of the carbon fibers. In order to observe the dispersion of the carbon fibers in the cement mortars prepared for this study, CT scan images of the samples were viewed and investigated.

\section{Evaluation of CT scan images of the samples}

CT scan images of the samples that were incorporated with/without carbon fibers (CF) were presented in Figure 1. These images obtained from the samples that have the flexural results for the 2- and 7-days curing ( $M_{1}, M_{2}$ and $\left.M_{6}\right)$. The main reason of selecting these samples can be explained as; $M_{1}$ is the control sample, on the other hand $M_{2}$ is the other sample that represents the highest flexural strength in all over the samples. And also, $M_{6}$ is the sample that has the highest amount of carbon fiber. After the flexural strength test was conducted on these samples, CT scan images of the samples were investigated. According to the test results, the carbon fibers could only be viewed at the cracking point of the samples for 2-day curing. The sand particles in the matrix could be observed as prominently. The structures that were observed in 2 day-curing samples are very similar to the each other. Not only the images of the $M_{1}$ and $M_{2}$ are similar to the each other, but also their flexural strength results are also very close to each other (4.8 $\mathrm{MPa}$ and 5.0 MPa, respectively). However, the images for M6 sample were observed as different from the other mixes. This situation was reflected as a reduction for the flexural strength of $\mathrm{M}_{6}$ sample (3.5 MPa). The highest differences between the samples were observed for 7 day-curing samples. The images for $M_{1}$ and $M_{2}$ mixes at 7-day curing are very similar to the 2 day-curing samples, and also their flexural strength are very close to the each other (7.0 MPa and 7.2 MPa, respectively). However, this situation is so different for $\mathrm{M}_{6}$ mix at 7-day curing. Due to the fact that $M_{6}$ for 7-day curing includes huge amount of carbon fiber, the reflection of CT scan images of the sample that was caused by the deformations existed as result of being exposed to flexural strength were different from the other samples. As it is clearly seen from the Figure $1 \mathrm{f}$, the thicker line shown in the image for $\mathrm{M}_{6}$ at 7-day curing, which is thought because of increasing of deformation time as a result of bending of the sample by flexural test, is so remarkable. The non-continuous bending lines observed at the images of the other samples are not clear compared to $\mathrm{M}_{6}$ sample for 7-days curing. Moreover, the flexural strength of M6 for 2-day curing in its own serie is the lowest value as it was expected (5 MPa). 
Figure 1. The CT scan images for: (a-c) $M_{1}, M_{2}$ and $M_{6}$ for 2-day curing, respectively, (d-f)

$M_{1}, M_{2}$ and $M_{6}$ for 7-day curing, respectively.
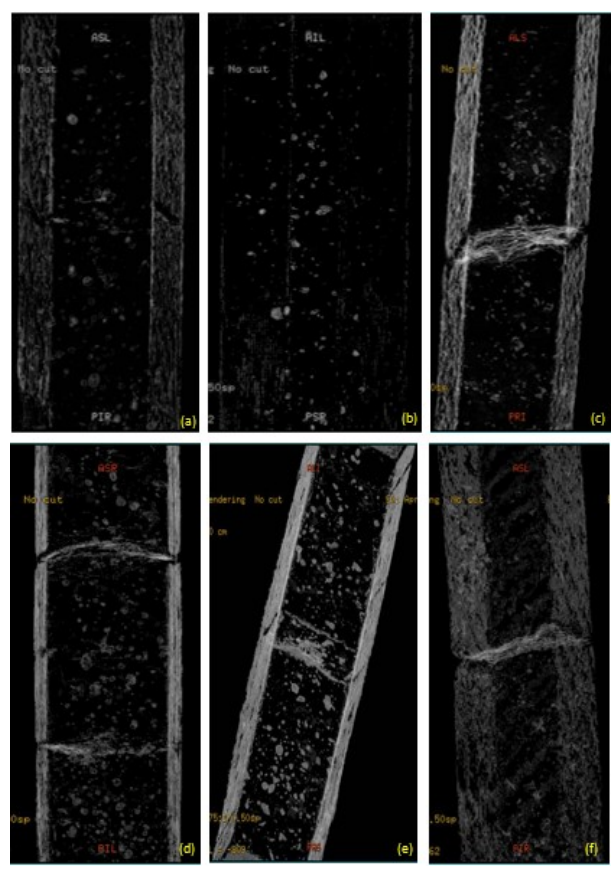

On the other hand, the high definition cross section and side views of $M_{1}, M_{2}$ and $M_{6}$ samples were given in Figures $2-$ 4 , respectively. According to Figure 2, carbon fibers cannot be seen in the pictures in order to prepare without carbon fiber. However, carbon fibers can be observed easily, especially for $M_{6}$ sample as seen in Figures 3 and 4 . As it is clearly understood from the figures that the orientation of the carbon fibers in the mortars is not uniform. As it aforementioned before, the dispersion of the carbon fibers has an important effect on compressive- and flexuralstrength of the sample. Because of this non-uniformity, the reductions shown in compressive and flexural strength of the samples may be explained.

Figure 2. High definition cross section and side views of $\mathrm{M}_{1}$ sample at 2-day curing (without $\mathrm{CF}$ )

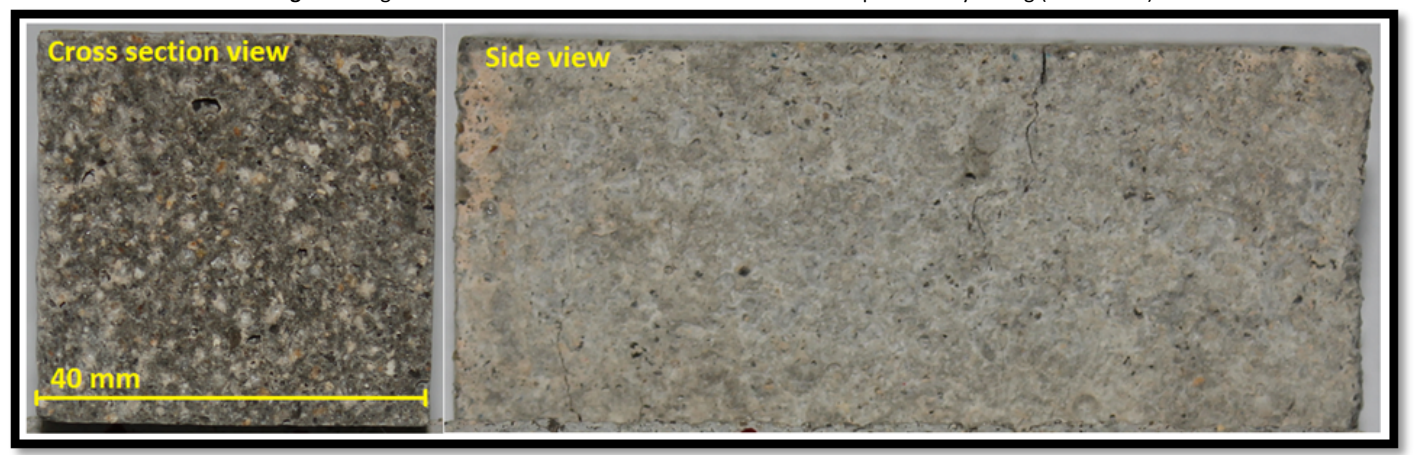

Figure 3. High definition cross section and side views of $\mathrm{M}_{2}$ sample at 7-day curing (with $\mathrm{CF}$ ). 


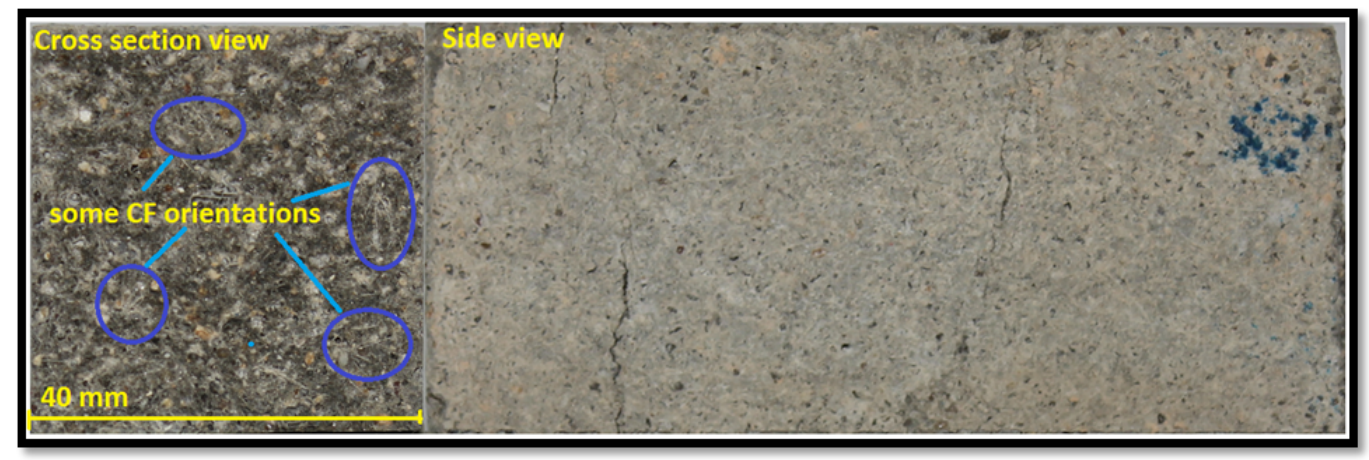

Figure 4. High definition cross section and side views of $\mathrm{M}_{6}$ sample at 7-day curing (with CF).

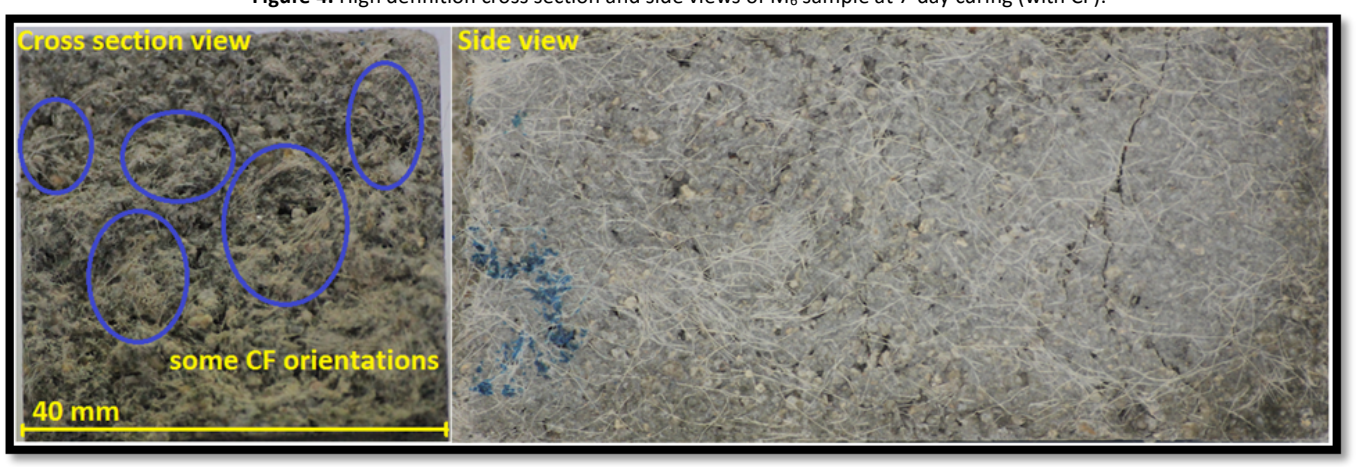

Conclusions

The study presents multi-slice computed tomography (CT) system to obtain the views and espoused optical microscope to observe the distribution of various constituents in the mixtures incorporated with carbon fiber (CF) after the flexural strength test. From the test results the following conclusions can be drawn:

- Due to the fact that large amounts of carbon fibers are more difficult to disperse uniformly and fibers form clusters and create more micro-defects in cement matrix, the reductions in the compressive and flexural strength of the samples were observed.

- The values of flexural strength of cement composites decreased with increasing of carbon fiber amount at all curing days. However, only $\mathrm{M}_{2}$ mixture at 2- and 7-days curing increased the flexural strength, slightly.

- The structure of the samples at the interfacial between carbon fiber and matrix is the most significant field that influences effectiveness of the carbon fibers.

- The highest differences between the samples were observed for 7 day-curing samples. The images for $M_{1}$ and $M_{2}$ samples at 7-day curing are as same as the 2 day-curing samples, and also their flexural strength values are very near to the each other.

- Although the test results for $M_{1}$ and $M_{2}$ are very similar to the each other, this condition is different for $M_{6}$ mixture in these mixes for all curing days. The main reason of this difference may be explained by the amount of carbon fiber in the matrixes.

- As it was estimated that non-uniformity of the carbon fibers in the samples caused a reduction for compressive and flexural strength of the samples.

References

ASTM (2015). ASTM C150M-15: Standard Specification for Portland Cement. ASTM.

Baeza, F. J., Galao, O., Zornoza, E. \& Garcés, P. (2013). Effect of aspect ratio on strain sensing capacity of carbon fiber reinforced cement composites. Materials \& Design, 51(10), 1085-1094. http://dx.doi.org/10.1016/j.matdes.2013.05.010

Cao, J. \& Chung, D. D. L. (2001). Carbon fiber reinforced cement mortar improved by using acrylic dispersion as an admixture. Cement and Concrete Research, 31(11), 1633-1637. http://dx.doi.org/10.1016/s0008-8846(01)00599-3

Chacko, R. M., Banthia, N. \& Mufti, A. A. (2007). Carbon-fiber-reinforced cement-based sensors. Canadian Journal of Civil Engineering, 34(3), 284290. http://dx.doi.org/ 10.1139/106-092 
Cosmi, F. \& Bernasconi, A. (2013). Micro-CT investigation on fatigue damage evolution in short fibre reinforced polymers. Composites Science and Technology, 79, 70-76. http://dx.doi.org/10.1016/j.compscitech.2013.02.008

Gao, J. M., Qian, C. X., Wang, B. \& Morino, K. (2002). Experimental study on properties of polymer-modified cement mortars with silica fume. Cement and Concrete Research, 32(1), 41-45. http://dx.doi.org/10.1016/S0008-8846(01)00626-3

Grace, N. F. \& Singh, S. B. (2005). Durability evaluation of carbon fiber-reinforced polymer strengthened concrete beams: experimental study and design. ACI Structural Journal, 102(1), 40-53.

Graham, R. K., Huang, B., Shu, X. \& Burdette, E. G. (2013). Laboratory evaluation of tensile strength and energy absorbing properties of cement mortar reinforced with micro-and meso-sized carbon fibers. Construction and Building Materials, 44, 751-756. http://dx.doi.org/10.1016/j.conbuildmat.2013.03.071

Kezhi, L., Chuang, W., Hejun, L., He-jun, L., Xin-tao, L., Hai-bo, O. \& Jian, W. (2008). Effect of chemical vapor deposition treatment of carbon fibers on the reflectivity of carbon fiber-reinforced cement-based composites. Composites Science and Technology, 68(5), $1105-1114$. http://dx.doi.org/10.1016/j.compscitech.2007.08.003

Lee, B. Y., Kim, J. K., Kim, J. S. \& Kim, Y. Y. (2009). Quantitative evaluation technique of Polyvinyl Alcohol (PVA) fiber dispersion in engineered cementitious composites. Cement and Concrete Research, 31(6), 408-417. http://dx.doi.org/10.1016/j.cemconcomp.2009.04.002

Liu, J., Li, C., Liu, J., Cui, G. \& Yang, Z. (2013). Study on 3D spatial distribution of steel fibers in fiber reinforced cementitious composites through micro-CT technique. Construction and Building Materials, 48, 656-661. http://dx.doi.org/10.1016/j.conbuildmat.2013.07.052

Mnahoncakova, E., Vejmelka R., Jirickova M., Cerny, R., Rovnanikova, P. \& Bayer, P. (2005). Thermal and hygric parameters of carbon-fiberreinforced cement composites after thermal and mechanical loading. Journal of Building Physics, 29(2), 121-143. https://dx.doi.org/10.1177/1744259105057223

Ozyurt, N., Mason, T. O. \& Shah, S. P. (2007). Correlation of fiber dispersion, rheology and mechanical performance of FRCs, Cement and Concrete Composites, 29(2), 70-79. http://dx.doi.org/10.1016/j.cemconcomp.2006.08.006

Ozyurt, N., Woo, L. Y., Mason, T. O., Shah, S. P. (2006). Monitoring fiber dispersion in fiber reinforced cementitious materials: comparison of ACimpedance spectroscopy and image analysis. ACI Materials Journal, 103(5), 340-347.

Rao, G. A. (2003). Investigations on the performance of silica fume-incorporated cement pastes and mortars. Cement and Concrete Research, 33(11), 1765-1770. http://dx.doi.org/10.1016/S0008-8846(03)00171-6

Sadrmomtazi, A., Fasihi, A. \& Haghi, A. K. (2009). Effect of polypropylene fibers on mechanical and physical properties of mortars containing nanoSiO2. In $3^{\text {rd }}$ International Conference on Concrete \& Development (1163-1172). Tehran, Iran.

Shui, Z. \& Stroeven, P. (1999). Uniformity assessment of carbon fibers dispersion in cement paste by impedance measurements. The Journal of Wuhan University of Technology-Materials Science, 14(1), 52-57.

Torigoe, S.I., Horikoshi, T., Ogawa, A., Saito, T., Hamada, T. (2003). Study on evaluation method for PVA fiber distribution in engineered cementitious composite. Journal of Advanced Concrete Technology, 1(3), 265-278. http://dx.doi.org/10.3151/jact.1.265

Wang, C., Li, K. Z., Li, H. J., Jiao, G. S., Lu, J. \& Hou, D. S. (2008). Effect of carbon fiber dispersion on the mechanical properties of carbon fiberreinforced cement-based composites. Materials Science and Engineering: A, 487(1-2), 52-57. http://dx.doi.org/10.1016/j.msea.2007.09.073

Woo, L. Y., Wansom, S., Ozyurt, N., Mu, B., Shah, S. P. \& Mason, T. O. (2005). Characterizing fiber dispersion in cement composites using ACimpedance spectroscopy. Cement and Concrete Composites, 27(6), 627-636. http://dx.doi.org/10.1016/j.cemconcomp.2004.06.003

Wang, Z. J. \& Xiao, J. J. (2012). Evaluation of air void distributions of cement asphalt emulsion mixes using X-ray computed tomography scanner. Journal of Testing and Evaluation, 40(2), 485-490. https://dx.doi.org/10.1520/JTE103881

Zhandarov, S. \& Mäder, E. (2005). Characterization of fiber/matrix interface strength: applicability of different tests, approaches and parameters. Composites Science and Technology, 65(1), 149-160. http://dx.doi.org/10.1016/j.compscitech.2004.07.003 